\title{
High prevalence of a missense mutation of the glucokinase gene in gestational diabetic patients due to a founder-effect in a local population
}

\author{
P.J.Saker ${ }^{1}$, A.T.Hattersley ${ }^{1}$, B. Barrow ${ }^{1}$, M.S.Hammersley ${ }^{1}$, J.-A.McLellan ${ }^{1}$, Y.-M. D. Lo ${ }^{2}$, R.J. Olds ${ }^{3}$, \\ M.D. Gillmer ${ }^{4}$, R. R.Holman ${ }^{1}$, R. C. Turner ${ }^{1}$ \\ ${ }^{1}$ Diabetes Research Laboratories, Radcliffe Infirmary, Oxford, UK \\ ${ }^{2}$ Nuffield Department of Pathology, John Radcliffe Hospital, Oxford, UK \\ ${ }^{3}$ Institute of Molecular Medicine, John Radcliffe Hospital, Oxford, UK \\ ${ }^{4}$ Nuffield Department of Obstetrics, John Radcliffe Hospital, Oxford, UK
}

Summary A high proportion of the female patients who are members of maturity onset diabetes of the young (MODY) pedigrees, and whose diabetes mellitus is due to a glucokinase mutation, originally presented with gestational diabetes. To establish whether glucokinase mutations could be a common cause of gestational diabetes, we studied 50 subjects who presented with gestational diabetes and on follow-up had hyperglycaemia (5.5-10.0 mmol/l). Screening for glucokinase mutations using single-stranded conformational polymorphism (SSCP) analysis detected a missense mutation at position 299 (Gly ${ }^{299} \rightarrow \mathrm{Arg}$ ) in three subjects. As two pedigrees in the Oxford area had the same glucokinase mutation, we suspected the role of a founder-effect, and carried out pedigree extension, haplotype construction (using microsatellite markers GCK1 and GCK2) and mutation screening of at-risk subjects from the same geographical area. One of the gestational diabetic subjects was found to be related to one of the previous pedigrees via her paternal grandmother. Subjects with the mutation were found to have the $Z+4 / 2$ (GCK1/ GCK2) haplotype, suggesting that the observed high prevalence of the Gly ${ }^{299} \rightarrow$ Arg glucokinase mutation in the Oxford region was due to a founder-effect. Since glucokinase mutations predominantly induce subclinical hyperglycaemia, it is likely that in the locality of other pedigrees there will be undiagnosed subjects with the same glucokinase mutation, which remains undetected unless pregnancy occurs. [Diabetologia (1996) 39: 1325-1328]

Keywords Non-insulin-dependent diabetes mellitus, gestational diabetes, glucokinase, single-stranded conformational polymorphism analysis, founder effect.
Glucokinase is a key enzyme in both the pancreatic beta cell and liver hepatocytes [1]. It catalyses the phosphorylation of glucose to glucose 6-phosphate. Mutations of the glucokinase gene have been described in subjects with maturity-onset diabetes mellitus of the young (MODY), and can affect up to

Received: 13 February 1996 and in revised form: 7 May 1996

Corresponding author: Dr. R.C.Turner, Diabetes Research Laboratories, Radcliffe Infirmary, Woodstock Road, Oxford, OX2 6HE, UK

Abbreviations: GDM, gestational diabetes; OGTT, oral glucose tolerance test; SSCP, single-stranded conformational polymorphism; MODY, maturity onset diabetes of the young; PCR, polymerase chain reaction; Gly ${ }^{299} \rightarrow \mathrm{Arg}$, glycine to arginine mutation at position 299.
$50 \%$ of MODY pedigrees [2]. In late-onset non-insulin-dependent diabetes, mutations of the glucokinase gene have been described in English and Japanese subjects [3-5]. However, linkage analysis, population association studies, and molecular screening all suggest that it is unlikely that mutations in the glucokinase gene cause more than $1 \%$ of diabetes in Caucasians diagnosed after the age of 40 years [6-8].

We observed that subjects with glucokinase mutations often present with gestational diabetes (GDM) [9]. Of 11 parous women from two pedigrees (AX and $\mathrm{BX}$ ) with a missense mutation in exon 8 of the glucokinase gene (Gly ${ }^{299} \rightarrow$ Arg), seven were initially diagnosed with GDM [3, 9]. GDM has a similar clinical phenotype to subjects with MODY possessing a glucokinase mutation, in that they have an early age of onset, mild hyperglycaemia leading to 
Table 1. Clinical characteristics of the gestational diabetic subjects

\begin{tabular}{ll}
\hline & GDM subjects \\
\hline Number of subjects & 50 \\
Mean age (years) & $37.0 \pm 0.3$ \\
Years since diagnosis of GDM & $10.0 \pm 5.9$ \\
Fasting plasma glucose on follow-up (mmol/l) & $6.8 \pm 1.6$ \\
Mean BMI (kg/m ${ }^{2}$ ) & $29.0 \pm 3.4$ \\
Known family history of diabetes & $70 \%$ \\
\hline
\end{tabular}

Values are mean $\pm 1 \mathrm{SD}$

symptomatic diabetes in later life, and tend to have a strong family history of diabetes $[9,10]$. The frequency of glucokinase mutations in UK Caucasian subjects with GDM is not known. We therefore investigated the prevalence of GDM caused by mutations in the glucokinase gene by screening UK Caucasian subjects using the technique of single-stranded conformational polymorphism (SSCP) analysis.

\section{Subjects and methods}

Study population and DNA extraction. Fifty unrelated Caucasian subjects from the Oxford region of the UK who had been diagnosed as having GDM were studied. GDM was diagnosed on the basis of two abnormal values during an oral glucose tolerance test (OGTT) performed during pregnancy (at 2834 weeks) [11] and with hyperglycaemia (> 5.5-10 mmol/l) on follow-up (mean duration 10 years). Subjects known to be members of pedigrees AX and BX [3,9] were excluded from the study. The clinical characteristics of the subjects are shown in Table 1 . Blood samples from the 50 subjects were drawn into EDTA and DNA was extracted from whole blood using the standard phenol/chloroform method.

\section{Laboratory methods}

Mutation screening. Mutation screening of exons 2-10 was carried out using the technique of SSCP analysis [12]. Polymerase chain reaction (PCR) amplification was carried out using primers described previously $[13,14]$. For SSCP analysis, generally, $2 \mu \mathrm{l}$ of PCR product was run for $18 \mathrm{~h}$ at $350 \mathrm{~V}$ on $10 \%$ polyacrylamide gels under two conditions; with $5 \%$ glycerol at $25^{\circ} \mathrm{C}$ and without glycerol at $4^{\circ} \mathrm{C}$. A heater-cooler system was used to control the temperature (Bettatech, Milton Keynes, UK). Amplified DNA from a normoglycaemic subject, and for each exon a subject known to possess a glucokinase mutation, were run as negative and positive controls. Gels were visualised by silver staining (BioRad, Hemel Hempstead, Herts, UK).

Sequencing and restriction fragment length polymorphism (RFLP) analysis. Exons from subjects shown to have an abnormal band mobility were directly sequenced after isolating single-stranded DNA using biotinylated PCR primers and streptavidin-coated Dynabeads (Dynal, Bromborough, Merseyside, UK). The previously characterised missense mutation $\left(\right.$ Gly $^{299} \rightarrow$ Arg) was confirmed by a specific PCR generated RFLP using the restriction endonuclease Hha1 [3].

When a mutation was found, other members of the subject's family were contacted and tested for glucose tolerance

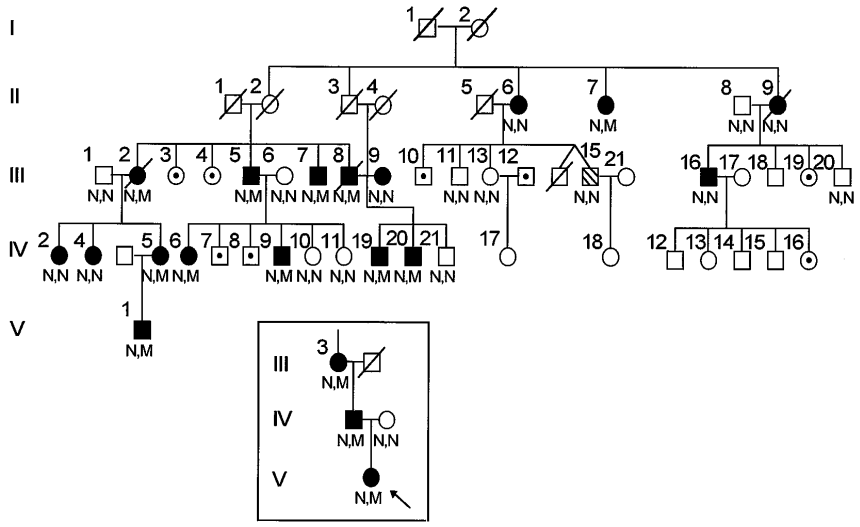

Fig. 1. Pedigree AX: a newly identified patient with gestational diabetes and the Gly ${ }^{299} \rightarrow$ Arg mutation is a member of a previously unavailable branch of the family. Prior to the present study, individual III-3 was unavailable for testing. $\square$, Males; $\bigcirc$, females; $\bigcirc$, diabetes; $\mathbb{N}$, glucose intolerance; open symbol, normoglycaemic; central dot, not tested; slash, dead; $\mathrm{N}$, normal allele; M, mutant allele; arrow indicated gestational diabetic proband

and the presence of the mutation by SSCP and the specific RFLP. Paternity was established using DNA finger-printing and highly polymorphic markers (Cellmark Diagnostics, Abingdon, Oxford, UK).

\section{Statistical analysis}

Values are given as mean \pm 1 SD. Haplotypes were constructed when a subject was homozygous of one or both of the GCK1 and GCK2 loci.

\section{Results}

Mutation screening. After screening the $50 \mathrm{GDM}$ subjects, abnormal band patterns were detected in exons $3(8 / 50), 8(3 / 50)$ and $9(12 / 50)$. These exons were also screened in normoglycaemic control subjects. The same abnormal band patterns were found in exons 3 and 9 in 8 of 50 and 12 of 50 control individuals, respectively. These results suggested that the abnormal band patterns seen for exons 3 and 9 were due to polymorphisms. Direct sequencing has failed to identify a base change resulting in a mutation or polymorphism in either of these two exons.

We have already described a mutation in exon 8 in two pedigrees ( $\mathrm{AX}$ and $\mathrm{BX})[3,9]$. The three unrelated subjects had a similar abnormal band pattern mobility to members of pedigrees $\mathrm{AX}$ and $\mathrm{BX}$ who possessed a glucokinase mutation. Direct sequencing and the use of the RFLP confirmed that these three subjects had the Gly ${ }^{299} \rightarrow$ Arg missense mutation found in pedigrees $\mathrm{AX}$ and $\mathrm{BX}$. This mutation in exon 8 has not been found to occur in 100 nondiabetic individuals screened using SSCP and the RFLP [3], or 52 ex-GDM subjects who were 
Table 2. Allele scores for the microsatellite markers GCK1 and GCK2 for subjects with the Gly ${ }^{299} \rightarrow$ Arg mutation. From these, haplotypes were constructed when at least one of the polymorphisms was homozygous

\begin{tabular}{llll}
\hline Subject & GCK1 & GCK2 & Haplotypes \\
\hline Pedigree $A X$ & & & \\
II-7 & $\mathrm{Z}, \mathrm{Z}+4$ & 2,2 & $\mathrm{Z}, 2 \mathrm{Z}+4,2$ \\
IV-5 & $\mathrm{Z}, \mathrm{Z}+4$ & 2,2 & $\mathrm{Z}, 2 \mathrm{Z}+4,2$ \\
IV-19 & $\mathrm{Z}, \mathrm{Z}+4$ & 2,2 & $\mathrm{Z}, 2 \mathrm{Z}+4,2$ \\
IV-20 & $\mathrm{Z}, \mathrm{Z}+4$ & 2,2 & $\mathrm{Z}, 2 \mathrm{Z}+4,2$ \\
V-1 & $\mathrm{Z}+2, \mathrm{Z}+4$ & 2,2 & $\mathrm{Z}+2,2 \mathrm{Z}+4,2$ \\
Pedigree BX & & & \\
IV-5 & $\mathrm{Z}, \mathrm{Z}+4$ & 2,2 & $\mathrm{Z}, 2 \mathrm{Z}+4,2$ \\
IV-9 & $\mathrm{Z}, \mathrm{Z}+4$ & 1,2 & \\
IV-10 & $\mathrm{Z}, \mathrm{Z}+4$ & 1,2 & \\
IV-19 & $\mathrm{Z}, \mathrm{Z}+4$ & 1,2 & \\
IV-33 & $\mathrm{Z}+4, \mathrm{Z}+4$ & 2,3 & $\mathrm{Z}+4,2 \mathrm{Z}+4,3$ \\
V-5 & $\mathrm{Z}+4, \mathrm{Z}+4$ & 2,2 & $\mathrm{Z}+4,2 \mathrm{Z}+4,2$ \\
Gestational diabetic patients & & \\
KD (AX) & $\mathrm{Z}, \mathrm{Z}+4$ & 2,2 & $\mathrm{Z}, 2 \mathrm{Z}+4,2$ \\
RW (AX) & $\mathrm{Z}+4, \mathrm{Z}+4$ & 2,2 & $\mathrm{Z}+4,2 \mathrm{Z}+4,2$ \\
MB & $\mathrm{Z}+4, \mathrm{Z}+4$ & 2,2 & $\mathrm{Z}+4,2 \mathrm{Z}+4,2$ \\
MA & $\mathrm{Z}+4, \mathrm{Z}+4$ & 1,2 & $\mathrm{Z}+4,1 \mathrm{Z}+4,2$ \\
\hline
\end{tabular}

normoglycaemic $(<5.5 \mathrm{mmol} / \mathrm{l})$ on follow-up (mean duration 10 years).

The families of two of these three GDM subjects were studied. In both, one parent and at least one other relative had diabetes and the mutation segregated with diabetes and glucose intolerance. The family of the third subject could not be studied.

Pedigree extension and haplotype construction. Five probands in the Oxford district had been found to have the same missense mutation in exon 8 of the glucokinase gene. To assess whether this was due to a founder-effect, we carried out pedigree extension and haplotype construction (using microsatellite markers GCK1 and GCK2).

Family records dating back to the mid-late 19th century were examined. We found that one of the GDM subjects was related via her paternal grandmother to a previously untested branch of pedigree AX.

Using the microsatellite markers GCK1 and GCK2, many of the subjects with the mutation were found to have the haplotype $Z+4 / 2$, for GCK1 and GCK2, respectively (Table 2). In those in whom it was not possible to assign a haplotype, the alleles did contain both $\mathrm{Z}+4$ and 2 , so the haplotype could have occurred.

Screening of further at-risk subjects from the same geographical area. Using the specific RFLP which detects the Gly ${ }^{299} \rightarrow$ Arg glucokinase mutation, we investigated 108 subjects from the same geographical area who on glycaemic testing had a fasting plasma glucose level in the range $5.5-7.8 \mathrm{mmol} / 1$, and had been entered into the Fasting Hyperglycaemia Study.
The majority of these individuals presented for screening because they had a first-degree relative with diabetes, or had raised blood glucose levels during pregnancy. The characteristics of these subjects are similar to those found in patients with glucokinase mutations $[15,16]$. None of these subjects had the Gly ${ }^{299} \rightarrow$ Arg glucokinase mutation.

\section{Discussion}

Mutation screening of 50 UK white Caucasian subjects who have had GDM identified three unrelated subjects with a missense mutation (Gly ${ }^{299} \rightarrow$ Arg) in exon 8 of the glucokinase gene. This particular mutation is the cause of their diabetic phenotype [10]. Our results would appear to suggest that glucokinase mutations occur in $6 \%$ of GDM subjects; this is likely to be a considerable over-estimation of the frequency. The cohort of subjects screened were those who had hyperglycaemia on follow-up, and represented approximately $50 \%$ of the GDM subjects at the time of their diagnosis. The incidence is further complicated by the presence of a founder-effect. Mutation screening by SSCP has identified glucokinase mutations in Caucasian [17, 18] and Hispanic [17] patients with GDM but not in African patients [14]. Up to 5$10 \%$ of GDM in white Caucasian patients and Hispanic patients may be due to mutations in the glucokinase gene $[17,18]$.

We have previously described the Gly ${ }^{299} \rightarrow$ Arg glucokinase mutation in two pedigrees (AX and BX) [3]. Expression studies have shown that this mutation reduces the $\mathrm{V}_{\max }$ of the enzyme to less than $1 \%$ of the native form [19], and we have found that 27 of the 28 individuals possessing the mutation had a fasting plasma glucose level of more than $6 \mathrm{mmol} / \mathrm{l}$. Of the five separate probands identified, one presented with MODY, one with non-insulin-dependent diabetes, and three with GDM.

This is the only glucokinase mutation to be described in four apparently unrelated probands. All reside in the Oxford district, whereas this mutation has not been described elsewhere. Pedigree extension revealed that one of the three GDM subjects was a member of a previously unknown branch of pedigree AX. Construction of haplotypes for those subjects with the glucokinase mutation in all five families found that they all have the $Z+4 / 2$ haplotype. This suggests that there was a founder-effect, and no recombination has taken place in recent evolutionary history. The observed frequency for this haplotype in British Caucasian non-diabetic control subjects is $17.6 \%$ [8]. The odds of the same haplotype occurring by chance alone if the four probands are unrelated is $(0.176)^{3} p=0.0054$.

We also investigated the prevalence of this particular glucokinase mutation in subjects who reside in the 
Oxford area who were found on screening to have a fasting plasma glucose level between $5.5-7.7 \mathrm{mmol} / \mathrm{l}$. None of these subjects had the Gly ${ }^{299} \rightarrow$ Arg glucokinase mutation. Thus, the diagnosis of GDM seems to be a particularly sensitive screen for glucokinase mutations. As glucokinase mutations predominantly present with a subclinical disease, it seems likely that undetected patients with glucokinase mutations would be identified on screening the local populations of other probands. Glucokinase mutations will particularly occur in those with GDM. The identification of glucokinase mutations in such patients can be helpful in indicating a good prognosis [10].

Acknowledgements. We are grateful for support from the Wellcome Trust, and Alan and Babette Sainsbury Trust; to Dr. P. Froguel for providing samples with known glucokinase mutations used as positive controls in the SSCP analysis; to Dr. S. L. Thein for assistance with direct sequencing; to Dr. G. Rysieki of Cellmark Diagnostics for paternity testing; and to Ms. I. Samuel and Ms. C. Wood for preparation of the manuscript. A. T.H. was an MRC Training Fellow. P. J.S. is currently at the Unit of Metabolic Medicine, Imperial College of Medicine, St. Mary's Hospital, London; A. T. H. is at Department of Vascular Medicine and Diabetes Research, University of Exeter; R.J.O. is at The Department of Pathology, University of Otago, Dunedin, New Zealand.

\section{References}

1. Matchinsky FM (1990) Glucokinase as glucose sensor and metabolic signal generator in pancreatic $\beta$-cells and hepatocytes. Diabetes 39: 647-652

2. Froguel Ph, Zouali H, Vionnet N et al. (1993) Familial hyperglycaemia due to mutations in glucokinase - definition of a subtype of diabetes mellitus. New Engl J Med 328: 697-702

3. Stoffel M, Patel P, Lo YM-D et al. (1992) Characterisation of a missense glucokinase mutation in maturity-onset diabetes of the young (MODY) and mutation screening in late-onset diabetes. Nature Genetics 2: 153-156

4. Sakura H, Eto K, Kadowaki H et al. (1992) Structure of the glucokinase gene and identification of a missense mutation in a Japanese patient with early-onset non-insulin dependent diabetes mellitus. J Clin Endocrinol Metab 75: 15711573

5. Katagiri H, Asano T, Ishihara H et al. (1992) Nonsense mutation of glucokinase gene in late-onset non-insulin dependent diabetes mellitus. Lancet 340: 1316-1317
6. Cook JTE, Hattersley AT, Christopher P et al. (1992) Linkage analysis of glucokinase gene with NIDDM in Caucasian pedigrees. Diabetes 41: 1496-1500

7. Elbein SC, Hoffman M, Chiu K, Tanizawa Y, Permutt MA (1993) Linkage analysis of the glucokinase locus in familial type 2 (non-insulin-dependent) diabetic pedigrees. Diabetologia 36: 141-145

8. Hattersley AT, Saker PJ, Cook JTE et al. (1993) Microsatellite polymorphisms at the glucokinase locus: a population association study in Caucasian type 2 diabetic subjects. Diabet Med 10: 694-698

9. Hattersley AT, Turner RC, Permutt MA et al. (1992) Linkage of type 2 diabetes to the glucokinase gene. Lancet 339: $1307-1310$

10. Page RCL, Hattersley AT, Levy JC et al. (1995) Clinical characteristics of subjects with a missense mutation in glucokinase. Diabet Med 12: 209-217

11. Gillmer MDG, Oakley NW, Beard RW et al. (1980) Screening for gestational diabetes during pregnancy. Br J Obstet Gynaecol 87: 377-387

12. Orita M, Suzuki Y, Seikya T, Hayashi K (1989) Rapid and sensitive detection of point mutations and DNA polymorphisms using the polymerase chain reaction. Genomics 5: 874-879

13. Stoffel M, Froguel Ph, Takeda J et al. (1992) Human glucokinase gene: isolation, characterisation, and identification of two missense mutations linked to early-onset noninsulin-dependent (Type 2) diabetes mellitus. Pro Natl Acad Sci USA 89: 7698-7702

14. Chiu KC, Tanizawa Y, Permutt MA (1993) Glucokinase gene variants in the common form of NIDDM. Diabetes 42: 579-582

15. Hattersley AT, Turner RC (1993) Mutations of the glucokinase gene and type 2 diabetes. Quarterly Journal of Medicine Vol 86: 222-232

16. Froguel P, Zouali H, Vionnet N, Velho G, Vaxillaire M, Sun F (1993) Familial hyperglycaemia due to mutations in glucokinase - definition of a subtype of diabetes mellitus. $\mathrm{N}$ Engl J Med 328: 697-702

17. Zouali H, Vaxillaire M, Lesage S et al. (1993) Linkage analysis and molecular scanning of glucokinase gene in NIDDM families. Diabetes 42: 1238-1245

18. Stoffel M, Bell KL, Blackburn CL et al. (1993) Identification of glucokinase mutations in subjects with gestational diabetes mellitus. Diabetes 42: 937-940

19. Gidh-Jain M, Takeda J, Wu LZ, Lange AJ et al. (1993) Glucokinase mutations associated with non-insulin-dependent (type 2) diabetes mellitus have decreased enzymatic activity: implications for structure/function relationships. Pro Natl Acad Sci USA 90: 1932-1936 